\title{
Evaluation of the relative weight (RW) of diagnosis-related groups (DRG) in critically ill patients (CIP) with severe sepsis (SS) according to the major diagnostic categories (MDC)
}

\author{
J Ruiz Moreno ${ }^{1 *}$, E González Marín', MJ Esteve Paños ${ }^{1}$, R Corcuera Romero de la Devesa', MJ Riba Ribalta', \\ S Godayol Arias', N Conesa Folch', F Baigorri González', A Artigas Raventós²
}

From ESICM LIVES 2015

Berlin, Germany. 3-7 October 2015

\section{Introduction}

Apart from financial purposes (cost accounting), DRG as case - mix system are not used for obtaining competitive advantage. The variability of the RW of DRG related to SS has not been researched; it could be relevant from a socioeconomic perspective. In relation with SS, we hypothesize that the average RW of each MDC is different.

\section{Objectives}

Analyze if the RW of the DRGs in CIPs with SS behaves differently depending on the MDC.

\section{Methods}

- Type of Study: prospective, analytical, longitudinal, and observational

- Period: January 1-2011 / June 30-2014 (42 months)

- Setting : Medical/Surgical ICU

- Population: 2559 CIPs admitted consecutively to the ICU; sample: 484 CIPs with SS.

- Exclusión criteria: CIPs < 16 y., major burn CIPs, incomplete clinical documentation, and voluntary discharge.

- DRG AP-DRG 25.0 version (684 DRG are grouped into 25 Major Diagnostic Categories and 1 extra Category). Each DRG can be medical (M) or surgical (S).

- MDC: 1 (neurology), 2 (eye), 3 (ear, nose, mouth, throat), 4 (respiratory), 5 (circulatory), 6 (digestive,

${ }^{1}$ QuirónSalud Hospital Universitario Sagrat Cor, Critical Care Department,

Barcelona, Spain

Full list of author information is available at the end of the article
7 (hepatobiliary \& pancreas), 8 (musculoskeletal \& connective), 9 (skin \& breast), 10 (endocrine), 11 (urinary tract), 12 (male reproductive), 13 (female reproductive), 14 (pregnancy \& childbirth), 15 (newborn), 16: (blood \& immunological), 17 (mMyeloproliferative), 18 (infectious), 19 (mental), 20 (alcohol / drug), 21 (Injuries \& poison), 22 (burns), 23 (factors influencing health status), 24 (HIV), 25 (PLT), 0 (PreMed, miscellany)

- Excluded MDC: 8 DRG with SS

- Depending on the focus of sepsis, SS related to MDC '0' (extra Category) are transferred to another MDC.

- Statistical analysis: ANOVA, 'F' Snedecor. Scheffe's test post ANOVA to find out which pairs of MDC are significative.

\section{Results}

See Tables 1 and 2 .

- Excluded MDC: 2, 3, 4, 12,13,14, 15, 16, 17, 19, 20 , 21, 22, 23, 24 y 25

- Significative ANOVA (F Snedecor $=5,6633, \mathrm{P}<$ $0,001)$ :

\section{Conclusions}

- The RW of MDC ' 4 ' and ' 6 ' is greater than the RW of the rest of the MDC.

- The RW of the rest of MDC are quite similar.

- MDC '4' and '6' differ, respectively, with 6 and 3 MDC.

\section{SpringerOpen $^{\circ}$}

(c) 2015 Ruiz Moreno et al.; This is an Open Access article distributed under the terms of the Creative Commons Attribution License (http://creativecommons.org/licenses/by/4.0), which permits unrestricted use, distribution, and reproduction in any medium, provided the original work is properly cited. 
Table 1. Results I

\begin{tabular}{llllllllll}
\hline MDC & $\mathbf{8}$ DRG) & $\mathbf{4}$ (114 DRG) & $\mathbf{5}$ (30 DRG) & $\mathbf{6}$ (152 DRG) & $\mathbf{7}$ (94 DRG) & $\mathbf{8}$ (14 DRG) & $\mathbf{9}$ (8 DRG) & $\mathbf{1 1}$ (22 DRG) & $\mathbf{1 8}$ (33 DRG) \\
\hline RW & 8,46 & 11,06 & 6,19 & 9,93 & 4,50 & 5,11 & 4,03 & 5,16 & 3,76 \\
\hline MDC 1 (8 DRG) & NS & NS & NS & NS & NS & NS & NS & NS & NS \\
\hline MDC 4 (114 DRG) & NS & & 0,01495 & NS & 0,0001 & 0,03020 & 0,04719 & 0,00989 & 0,00047 \\
\hline MDC 5 (30 DRG) & NS & $0,01495 S$ & & NS & NS & NS & NS & NS & NS \\
\hline MDC 6 (152 DRG) & NS & NS & NS & & 0,00015 & NS & NS & 0,03095 & 0,00165 \\
\hline MDC 7 (94 DRG) & NS & 0,0001 & NS & 0,00015 & & NS & NS & NS & NS \\
\hline
\end{tabular}

Table 2. Results II

\begin{tabular}{|c|c|c|c|c|c|c|c|c|c|}
\hline MDC & 1 (8 DRG) & 4 (114 DRG) & 5 (30 DRG) & 6 (152 DRG) & 7 (94 DRG) & 8 (14 DRG) & 9 (8 DRG) & 11 (22 DRG) & $18 / 33$ DRG) \\
\hline RW & 8,46 & 11,06 & 6,19 & 9,93 & 4,50 & 5,11 & 4,03 & 5,16 & 3,76 \\
\hline MDC 8 (14 DRG) & NS & 0,03020 & NS & NS & NS & & NS & NS & NS \\
\hline MDC 9 (8 DRG) & NS & 0,04719 & NS & NS & NS & NS & & NS & NS \\
\hline MDC 11 (22 DRG) & NS & 0,00989 & NS & 0,03095 & NS & NS & NS & & NS \\
\hline MDC 18 (33 DRG) & NS & 0,00047 & NS & 0,00165 & NS & NS & NS & NS & \\
\hline
\end{tabular}

\section{Authors' details}

${ }^{1}$ QuirónSalud Hospital Universitario Sagrat Cor, Critical Care Department,

Barcelona, Spain. ${ }^{2}$ Hospital de Sabadell \& QuirónSalud Hospital Universitario

Sagrat Cor, Critical Care Department, Sabadell, Spain.

Published: 1 October 2015

doi:10.1186/2197-425X-3-S1-A766

Cite this article as: Ruiz Moreno et al:: Evaluation of the relative weight

(RW) of diagnosis-related groups (DRG) in critically ill patients (CIP) with severe sepsis (SS) according to the major diagnostic categories (MDC).

Intensive Care Medicine Experimental 2015 3(Suppl 1):A766.

Submit your manuscript to a SpringerOpen ${ }^{\mathcal{O}}$ journal and benefit from:

- Convenient online submission

- Rigorous peer review

- Immediate publication on acceptance

- Open access: articles freely available online

- High visibility within the field

- Retaining the copyright to your article 